\section{O pensamento propagandístico japonês, das origens até 1945}

\section{[The Japanese propagandistic thought, from the origins until 1945]}

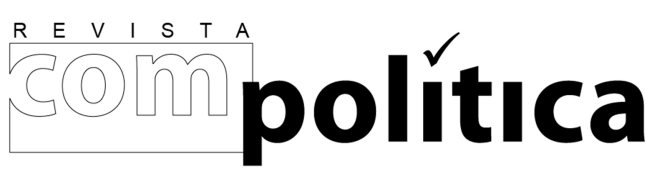

revista compolítica 2016, vol. 6(1)

compolitica.org/revista

ISSN: 2236-4781

DOI: $10.21878 /$ compolitica.2016.6.1.220

O. Open Access Journal

\author{
Francisco Rüdiger \\ Universidade Federal do Rio Grande do Sul e \\ Pontifícia Universidade Católica do Rio Grande do Sul \\ [Federal University of Rio Grande do Sul and Pontifical \\ Catholic University of Rio Grande do Sul]
}

\begin{abstract}
Resumo
O Japão foi um dos protagonistas do movimento que, após a I Guerra Mundial, transformou a propaganda em objeto de reflexão teórica nos grandes centros acadêmicos e intelectuais de todo o mundo. $O$ artigo apresenta a primeira notícia em língua portuguesa a respeito deste assunto. A primeira seção relata as origens do fenômeno e peculiaridades do contexto histórico e sociológico em que ele se desenvolveu. A segunda analisa as circunstâncias e ideias que marcaram seu auge, coincidente com o último estágio de expansão do imperialismo japonês. O terceiro detalha as concepções de Koyama Eizō, talvez o seu maior pensador.
\end{abstract}

Palavras-chave: estudos de propaganda; Japão; história do pensamento comunicacional.

\begin{abstract}
Japan was one of the major players in the movement that, after the World War I, transformed propaganda in an object of theoretical reflection in large academic and intellectual centers in the world. The article presents a first draft in Portuguese on that subject. Initially we present the origins of the phenomenon and the peculiarities of the historical and sociological context in which it was developed. The following section analyzes the circumstances and ideas that marked its peak, which coincided with the last stage of the Japanese imperialism expansion. The third one details the theories of Koyama Eizō, probably its greatest thinker.
\end{abstract}

Keywords: propaganda studies; Japan; history of communication thought. 


\section{O pensamento propagandístico japonês, das origens até 1945}

\section{Francisco RÜDIGER}

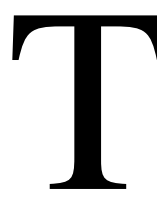

erminada a I Guerra Mundial, "propaganda”, praticamente de imediato, se converteu em termo corrente para, entre o público intelectualizado, designar o conjunto de ações, noções, técnicas, instrumentos e meios com que um coletivo ou instituição pretende, se não comandar, pelo menos influenciar a conduta e o pensamento de um grupo ou população. Oriundo da esfera religiosa, o termo se tornara popular no século XIX, com o significado de doutrinação política e partidária levada a cabo por conservadores, liberais e social-democratas. A radicalização, no entendimento de seu significado, proposta pelos anarquistas soava, naquele contexto, tão "disparatada", que era virtualmente nulo seu impacto na falta de acento polêmico, que caracterizava a expressão à época.

O emprego em larga escala de novas técnicas e recursos, o cunho coercitivo e atemorizador assumido pelas suas ações mais fortes e, por fim, a denúncia das fraudes cometidas por seu intermédio no curso do conflito ensejaram uma rápida mudança nesta visão. A guerra e, em seguida, o crescente emprego das ações e técnicas de propaganda nela surgidas por parte dos movimentos extremistas de esquerda e de direita, para não falar de sua assimilação mais ou menos cotidiana às rotinas dos governos e empresas, não apenas difundiram o termo, mas passaram a revesti-lo de forte mística e cunho problemático.

Nos países totalitários, a propaganda, endossada pelos apoiadores dos respectivos regimes, foi praticada de forma ampla, aberta e sistemática para suprimir as vozes dissonantes onde a repressão deixou um resto. Nos países democráticos, o fenômeno se manifestou de forma mais encoberta e menos regular, tendo sido objeto de disputa entre as várias forças políticas e sociais. $\mathrm{O}$ recurso às suas técnicas pela maior parte delas não impediu o surgimento de uma atitude de suspeita e, às vezes, de contestação em relação a seus benefícios, mormente entre a intelectualidade de formação liberal (cf. RÜDIGER, 2015). 
O presente trabalho se propõe a relatar a forma como o fenômeno da propaganda foi apropriado e repensado pelos intelectuais japoneses no período que precedeu o fim da II Guerra Mundial.

Após o conflito, o país voltou, em pouco tempo, a ter a proeminência que conquistara a partir de 1900, sem o lastro militar e as pretensões imperialistas que o levaram à destruição em 1945. O Japão é, atualmente, exemplo de país social e politicamente estável e desenvolvido, cuja robustez econômica e feitos tecnológicos o projetam com destaque no cenário internacional. A área de mídia é uma prova: há tempos conhecemos a pujança dos meios de comunicação e a influência mundial de sua indústria da cultura (ALLEN, SAKAMOTO, 2014; TSUTSUIT, 2011).

Apesar disso, os estudos de mídia feitos naquele país são, na comunidade acadêmica em geral, pouco conhecidos e, entre nós, totalmente desconhecidos. A bibliografia sobre a trajetória da imprensa e outros meios de comunicação, para não falar de suas várias manifestações é, para todos os períodos, bastante expressiva e facilmente acessível, se o interessado domina a língua inglesa. O panorama, contudo, muda radicalmente de figura, ao se tentar saber sobre as origens, a trajetória e as discussões que o rápido e formidável desenvolvimento da imprensa, dos negócios da indústria cultural e das práticas profissionais de comunicação geraram entre os intelectuais e acadêmicos japoneses.

Paralelamente a trabalho sobre a pesquisa em jornalismo e a título de tarefa complementar (RÜDIGER, 2016), apresenta-se neste artigo uma primeira notícia sobre os estudos de propaganda desenvolvidos pelos japoneses, das origens desta literatura até 1945. O autor, vale a pena notar, não domina a língua japonesa para, tivesse como acessálas conforme seu desejo, manejar as fontes primárias a respeito do assunto. A estratégia para elaborar o tema foi, por isso e em essência, recorrer aos trabalhos japoneses traduzidos ou material disponível em língua inglesa, visto também não ser o caso de têlos encontrado em outras ocidentais ao seu alcance.

O autor está ciente de que, embora inevitáveis em qualquer trabalho acadêmico, talvez mais do que em outros a circunstância de, neste, não se poder acessar as fontes primárias da maneira desejada impõe prejuízos e limitações ao estudo. A originalidade da proposta 
em língua portuguesa e o cunho sem par que sua formatação adquire à luz das poucas disponíveis em outros vernáculos ocidentais (cf. KUSHNER, 2006) (incluindo traduções de originais em japonês - cf. HIDEYA, 1955; SATO, 1998), todavia, justificam sua publicação, em sendo vista como ponto de partida ou guia de referência para investigações mais aprofundadas.

O relato se apresenta, pois, como uma síntese de pesquisa documental baseada na leitura e na análise de fontes secundárias, visando ordenar em esquema histórico-hermenêutico orientado pelo reconhecimento das transformações na política do estado japonês as características mais centrais do pensamento propagandístico surgido no país asiático. $\mathrm{O}$ repertório bibliográfico que se logrou levantar, saliente-se por fim, não é extenso mas, cremos, permite oferecer um retrato minimamente informado, para uma primeira abordagem, do que nos propusemos a fazer nesta empreitada, isto é: aprender sobre as origens e os primeiros desenvolvimentos dos estudos, problemas e reflexões teóricas sobre a propaganda não comercial no Japão até o final da II Grande Guerra.

\section{Os primórdios}

No Japão, propaganda é estrangeirismo que se apresentou reflexivamente no final da I Guerra Mundial, quando o Ministério do Interior, em 1918, mandou produzir um relatório intitulado A propaganda alemã, para analisar as ações dos representantes deste último país contra a presença dos japoneses, que lhes haviam tomado os territórios possuídos na China (YANG, 2010, p. 60). Ações por parte do governo japonês no campo do que mais tarde seria chamado de propaganda começaram a ser empreendidas de modo mais discernível no final do século XIX. A rápida conversão do país em potência regional não apenas contou com forte apoio da maior parte da imprensa, mas foi acompanhada de reformas institucionais que modernizaram o país, colocando-o em sintonia com o que havia de mais avançado no Ocidente.

Já nesta época, o governo procurou criar uma agência para recolher e difundir as informações de seu interesse, batendo de frente com o poderio da Reuters e os interesses 
do Império Britânico, que haviam assumido o controle deste serviço, ao fazerem o cabo telegráfico internacional chegar ao país em 1871 (AKAMI, 2012, p. 55). Abrindo escritórios locais e no exterior e apoiando serviços de intermediação com a imprensa, as autoridades visavam ter canais mais seguros para a transmissão de seus pronunciamentos e explorar a publicação de noticiário como forma de propaganda. Criadas com este fim em 1914, as agências Kokusai e Toho desempenharam este papel até 1926, quando foram fundidas em uma única, a Rengō.

No plano interno, havia um rápido e formidável desenvolvimento das empresas jornalísticas, que em nada ficavam a dever, em termos tecnológicos e de sofisticação intelectual, para não falar da prosperidade, às dos maiores centros internacionais quando findou o conflito de 1914 (cf. KANESADA, 1924; WILDES, 1927). As tiragens se aproximavam, em alguns casos, ao milhão de exemplares diários, revelando os altos índices de leitura entre a população. Apesar disso, o clima no país não era de liberdade e transparência. A formação e manifestação da opinião pública era fortemente cerceada, fazendo um observador notar que "jornais de nenhum outro país se encontram tão sujeitos à rígida regulação ou censura direta em tempo de paz quanto os do Japão" (MARTIN, 1918, p. 17).

O Japão se tornara um país moderno, mas as instituições não se desenvolveram democraticamente. O sistema escolar, responsável pela rápida alfabetização das massas, era rigidamente controlado pelo governo. As matérias de ensino possuíam forte acento doutrinário. A preocupação em reproduzir o espírito comunitário dominante no passado convergia com o interesse em promover o culto ao imperador por parte de muitos setores dominantes (DEL BENE, 2008, p. 15; HIDEYA, 1955). O processo de escolarização, é certo, incentivou a popularização da imprensa, que, aos poucos, foi se assemelhando em qualidade à ocidental, mas não eram poucos os obstáculos com que esta última se defrontava.

Sucessivas legislações impediam o pleno desenvolvimento da liberdade de expressão. Em 1909, a lei limitou a cobertura dos atos dos poderes do estado, penalizou o insulto ao imperador e proibiu a atividade de agitação contra o governo. Em 1911, foi criada uma polícia especial, que ficou conhecida popularmente como "polícia do pensamento", por 
vigiar e perseguir os dissidentes ideológicos do sistema imperial. O Governo também editou naquele ano uma lei da imprensa que, reforçando os critérios para censura, instituiu um maior controle das formas de expressão pública. Qualquer manifestação que as autoridades julgassem subversiva da ordem pública podia ser proibida e levar os responsáveis à cadeia. Concebida para perseguir os grupos de esquerda, a Lei de Preservação da Segurança Pública de 1925 radicalizou este viés, criminalizando a formação de organizações e difusão de ideias ameaçadoras da política nacional e da propriedade privada (cf. SHILLONY, 1981; KASZA, 1988).

A situação, observe-se, não significa que inexistisse pluralismo de opiniões, nem que se desconhecesse a dissidência ideológica, variável em grau e intensidade de acordo com a conjuntura. A imprensa operava sob controles e censura, mas não era instrumento de propaganda do governo: havia uma relativa autonomia em sua atuação. Os jornais convergiam ou não com os interesses do governo, conforme a convicção de suas redações e, onde passaram à condição de grande negócio, as suas conveniências mercadológicas (cf., p. ex., MACDERMID, 1982).

A propaganda de guerra e tudo o mais que ela importou ao ser assimilada pelos movimentos totalitários e posta em prática por governos e organizações civis, após o conflito de 1914, chegou ao conhecimento dos intelectuais japoneses neste contexto. A forte desconfiança que o fenômeno começava a despertar entre número crescente de observadores ocidentais, contudo, também se fez presente no país. Os comunistas, ao contrário, empunharam o termo, e seus teóricos o elaboraram de acordo com a cartilha bolchevista, procurando pô-la em prática, através do trabalho de agitação entre os setores populares e a criação de uma imprensa partidária (SCHÄFER, 2012, p. 103-105).

A circunstância colaborou para sua pouca aceitação entre os setores mais intelectualizados da população, que o descartaram lançando mão de outros, como informação (joho), publicidade (senden) e publicidade comercial (kōkoku) (cf. EARHART, 2008, p. 492; COOPER, 1997). As autoridades civis e militares seguiram a tendência, mas aos poucos foram desenvolvendo iniciativas para estudar o papel do fenômeno nas relações internacionais. 
Havia vontade de conhecer as discussões e análises que emergiram do conflito de 1914, com base na convicção de que a superioridade das técnicas de propaganda dos Estados Unidos havia sido um componente essencial para sua marcha vitoriosa na Europa (BRONSON, 2012, p. 84).

Segundo Takashi Kenmochi (2013), o primeiro tratado dedicado ao assunto foi escrito com o próprio nome, "Puropropaganda", como título em 1930, por Tetsuo Konishi. A obra inicia explicando o significado do termo, ilustrando-o com a pregação contra os imigrados japoneses feita nos Estados Unidos no início do século XX. Amparando-se em Lasswell, a quem entrevistara durante seu período de estudos naquele país, o autor conta rapidamente a história da propaganda, dando especial relevo à análise do Comitê Creel (cf. CREEL, 1920). Para o japonês, a Guerra revelou o poder da propaganda, estimulando o desenvolvimento do estudo desse fenômeno. A aproximação proposta por ele chama atenção para seus meios, suas formas de exploração e a necessidade de seu planejamento e sistematização. A obra também compara e distingue a propaganda política da propaganda comercial, concedendo destaque ao papel da primeira nas períodos de eleições. Os fundamentos da matéria aparecem no capítulo final, que analisa o fenômeno a partir das leis da imitação (Tarde) e da psicologia das multidões (Le Bon).

Yutaka Tanaka não foi muito mais longe em seu tratado Guerra e Propaganda (1931). Impressionado com seu uso durante a Guerra, destaca o autor que, em essência, propaganda não é senão uma forma de expandir a consciência no tempo e no espaço. Formado em direito, para este alto funcionário do estado, a propaganda não seria, no âmago, mais que uma forma de superação do emprego da violência nas relações humanas. A forma com que o entendimento recíproco se desenvolve sem uso da força. A obra lança mão de uma abordagem historicista para demonstrar sua tese, mostrar o papel da propaganda na difusão e aceitação das ideias.

Para ele, a conexão entre as religiões monoteístas surgidas a partir do judaísmo (cristianismo e islamismo), como aquela existente entre as ideias que levam do helenismo ao renascentismo, ilustrariam sua tese: sem proselitismo, estes movimentos não teriam ajudado a transformar o mundo em um sentido que, no final das contas, é positivo para a 
humanidade. A ruptura se dá na era moderna, momento em que, submetida ao império da técnica sem alma e dominada pelo interesses materialistas, a propaganda é pervertida e passa a ser encarada como arma de guerra.

Após a reação internacional negativa à crise de 1931 com a China e à criação pelos japoneses do estado-títere do Manchukuo, considerada um fracasso para o país, ao levá-lo a sair da Sociedade das Nações, os militares decidiram converter a propaganda em prioridade, estabelecendo um Escritório de Informação, para estudar, planejar e orientar a comunicação pública com o exterior (cf. YUKA, 2013). Por outro lado, os episódios significaram "um novo passo na política de autocontrole dos meios de comunicação, que [em geral] abdicaram da missão de defender o direito à liberdade de informação, ao se transformarem, ainda que por razões econômicas, em caixa de repercussão propagandística do governo" (DEL BENE, 2008, p. 131).

Quando começou a guerra contra a China, em 1937, as autoridades promoveram o Comitê interministerial de Informação criado no ano anterior à condição de divisão da Secretaria do Interior, dotando-lhe de mais pessoal e recursos, com o objetivo de engajar a população japonesa no esforço militar. Declarou-se o evento oportunidade para o país mostrar a si mesmo "o poder da propaganda", como disse Yokomizo Kōki, oficial do órgão, em 1938 (apud YUKA, 2013, p. 161). Formado por profissionais do ramo, jornalistas e acadêmicos, além de políticos e militares, o comitê tinha por missão: "1) controlar e coordenar as informações consideradas fundamentais para a realização da política nacional; 2) controlar e coordenar os fluxos de informação interno e externo; e 3) controlar e coordenar a atividade de propaganda" (DEL BENE, 2008, p. 154).

Ainda em 1936, as agências de notícia que prestavam serviço ao governo foram nacionalizadas e, a partir de sua fusão, criou-se um órgão mais moderno e bem aparelhado, a Dōmei (MIMURA, 2011, p. 119). A liderança japonesa percebeu que havia necessidade de intervir com mais força e eloquência junto à opinião pública mundial e manter o apoio popular às operações que estava desenvolvendo naquele país, sobretudo após o Massacre de Nanking (cf. CROSS, 2009; YUKA, 2013; DE LANGE, 1998, p. 135-164) . 
Conforme os militares passavam a tomar conta dos negócios do país e a expansão imperialista se instalou como centro da vida política, a propaganda não apenas foi trazida para o proscênio como passou a ser vista sob nova luz, embora o termo ainda não fosse comum fora dos círculos extremistas. A velha noção de kyōka, associada à ideia de educação e liderança moral por parte dos governantes, foi cedendo lugar ao termo senden, no sentido de propagação de ideias através de meios técnicos modernos (SATO, 1998, p. 300). O crescente tensionamento do cenário internacional, com o avanço do totalitarismo e o agravamento das tensões entre o mesmo e a democracia forneciam o clima mais geral. O ataque às colônias dos países ocidentais e o bombardeio de Pearl Harbor, que levou à guerra com os Estados Unidos, foram precedidos pela transformação do comitê em Secretariado de Informação (1940) (cf. HIDEYA, 1955).

\section{O auge}

O Secretariado foi criado com o objetivo de centralizar e coordenar as atividades de propaganda civil necessárias à condução da guerra por parte de um estado autoritário. $\mathrm{O}$ ponto a levar em conta por quem se interessa pelo assunto é que, relativamente ao mesmo, a prioridade do governo, no entanto, continuou sendo o cenário externo. A agência oficial de informação jamais perdeu sua condição de principal braço da repartição, jogando um papel fundamental na coordenação das atividades e manejo das informações da rede de veículos que os japoneses conseguiram criar durante o conflito.

As autoridades não deixaram de intervir internamente, recorrendo ao controle e à censura dos meios de comunicação onde não era preciso usar repressão e violência (como ocorria em relação aos grupos de esquerda). A condução da propaganda interna se caracterizou, contudo, por um trabalho de cooperação estabelecido mais ou menos livremente entre os oficiais do governo e as lideranças da sociedade civil, de acordo com os termos de um registro ideológico razoavelmente consensual, que ficou conhecido como shisōsen: guerra ideológica ou, mais propriamente, guerra de pensamento (cf. KUSHNER, 2006; SATO, 1998). 
Houve quem se baseando em Hitler, por exemplo, enxergasse na propaganda um meio tático para impor ideias mediante sua repetição sistemática e constante em condições de virtual violência, inclusive em relação aos japoneses (cf. JANG, 2007, p. 58-59). Kushner observa em estudo detalhado, porém, que esta perspectiva não foi aquela dominante na propaganda feita em solo pátrio durante o período. Os japoneses, incluindo boa parte das autoridades, não viam na propaganda uma forma de comandar sua população de cima para baixo. A proposta com que se apresentou não era, internamente, enganar as massas, ainda que isso tenha ocorrido, sobretudo quando as notícias passaram a ser predominantemente negativas, no final de 1943.

Inclusive os defensores de uma política cultural autoritária influenciada pelos nazistas evitavam ver no emprego de seus aparatos uma forma de impor objetivos puramente governamentais, entendendo-os como meios para liberar a consciência das massas das várias oposições que a dividiam (ricos e pobres, citadinos e campesinos, cultos e incultos etc.). Para eles, a construção de uma comunidade ainda mais integrada e engajada espiritualmente no sistema de guerra seria obtida com o monitoramento e o fornecimento de cultura para as massas pelo governo - mas não deveria ter um cunho coercitivo e instrumental, como ilustra o pensamento do teórico do rádio Kondo Hirato (cf. SHIRATO, 2010) ou do teórico do cinema Tsumura Hideo (cf. WADA-MARCIANO, 2008, p. 133-137).

Diretor do Secretariado de Informação do Gabinete a partir de 1940, Yokomizo Mitsuteru disse isso de modo mais geral em 1937, ao sustentar, contra os adeptos de uma visão mais mecanicista, que a tarefa dos programas de propaganda no país seria "fortalecer cada vez mais a expansão do espírito nacional, chave do chamamento feito ao povo para que ele mesmo ponha sob sua iniciativa a solução dos problemas nacionais" (apud KUSHNER, 2006, p. 21). Kushner nota que a propaganda foi um esforço tomado em conjunto pela liderança político-militar e os representantes da sociedade civil, apoiando-se em iniciativas tanto privadas quanto estatais. A tendência foi a coordenação das primeiras pelas segundas, todavia não se excluindo de todo a censura e a eventual coerção. A propaganda interna deveria constituir, segundo esta perspectiva, o cultivo cotidiano e de baixo para cima de valores e atitudes inatos à sociedade japonesa (2006, p. 21). 
Quando começou a guerra na China (1937), o governo convidou e reuniu as lideranças civis e empresariais, mais os principais formadores da opinião pública, com os estrategistas militares e seus especialistas em propaganda, decidindo-se, na oportunidade, pela criação do Movimento nacional de mobilização espiritual, cujos fins eram três:

\begin{abstract}
Em primeiro, assegurar a total unificação da vontade pública através do apelo ao patriotismo. O patriotismo e a lealdade significavam subordinação dos caprichos individuais à perfeição do estado. Em segundo, aumentar a produção de armamentos. O esforço cada vez maior de cada indivíduo deveria aumentar os controles muito severos sobre a produção estipulados nos artigos da lei de mobilização nacional. Em terceiro, conquistar total apoio para a agressão à China. Significava redefinir o "incidente" com aquele país de acordo com uma linguagem compatível com os sublimes ideais japoneses perpetuados pelo sistema educacional (HIDEYA, 1955, p. 10).
\end{abstract}

Apesar da pouca repercussão cotidiana até o ataque a Pearl Harbor (1941), fora o quesito econômico, o movimento passou a empreender uma série de ações visando conscientizar a população a respeito da guerra que o país estava movendo. Havia necessidade de todos, de uma forma ou outra, se engajarem em seu esforço, mobilizarem-se em seu favor, argumentavam seus promotores. O apoio da imprensa, contudo, não era especialmente notável, e o principal até aquele tempo seguiu sendo o planejamento estratégico e redução a umas poucas empresas das atividades jornalísticas, o emprego motivacional da radiodifusão, o controle e censura do noticiário e das artes, e o monitoramento dos indivíduos propensos a ter "pensamentos perigosos" (cf. TIPTON, 2008, p. 135; cf. ASAHI SHIMBUN, 2015, p. 71-82).

O fundamento doutrinário ou matriz ideológica da política de propaganda do país era, conforme notado, o conceito de guerra de pensamento, surgido entre os círculos militares e cuidadosamente elaborado e desenvolvido por seus intelectuais orgânicos a partir de meados dos anos 1930 .

A mente - dissertavam os porta-vozes daqueles círculos - é a fortaleza do estado. Se a mente vacila, muitos milhares de tanques perdem sua força, dezenas de milhares de sacrifícios são desperdiçados. A guerra de pensamento ataca a mente e ocorre em tempo de paz tanto quanto em tempo de guerra, no campo de batalha tanto quanto na frente doméstica. A guerra de pensamento é 
a guerra sem armamento que se luta em meio à vida cotidiana de todos nós. Por isso, tudo faz parte da guerra de pensamento, suas balas são feitas de luz, de som, de cores, de papel - não tem forma. Somos todos guerreiro na guerra de pensamento, carregando nas costas o destino de nossa nação. A ascensão ou queda do Japão será decidida pelo viés de nossa mente (Secretariado de Informação do Gabinete, 1940, apud EARHART, 2008, p. 134; cf. SATO, 1998).

"O Oriente, passaram a repetir com copiosa monotonia os doutrinadores da ideia, teria uma tradição de cooperação, harmonia, respeito mútuo, integração e unidade comunitária, em contraste com o egoísmo, rivalidades intermináveis, atritos e atitude imperialista dos ocidentais" (IRIYE, 1982, p. 5). A guerra de conquista em território chinês se articulara ideologicamente com o projeto de acabar com a dominação ocidental no continente. Havia um plano para construir um vasto espaço de cooperação econômica e desenvolvimento político liderado ditatorialmente pelos japoneses.

Koichi Kanda (1892-1972) foi, talvez, o primeiro de uma série a estudar a propaganda como instrumento desta guerra de pensamento que, pensava, se instalara entre os japoneses e o Ocidente. Para ele (Guerra de pensamento e propaganda, 1935, 2ed. 1937), o principal em relação à mesma não está no emprego da técnica, mas na compreensão da importância do pensamento, do fator subjetivo, como chamavam os marxistas, nas guerras do século XX. A guerra moderna não diz respeito apenas à guerra de material. A história revelaria que o pensamento e sua propagação têm, em todas as revoluções, um papel estratégico, que passou a ser cada vez mais organizado a partir da I Guerra Mundial. O Comitê Creel, mais que os jornais de Lord Northcliffe, examinados por ele em detalhe, são a melhor ilustração de um assunto para o qual os japoneses precisam se voltar, se é para sustentarem uma estratégia vitoriosa em meio ao novo mundo.

Oficial do Comitê de Informação criado pelo governo em 1936, o autor ainda escreveria dois pequenos textos no ano seguinte, em que caracteriza e examina as estratégias da propaganda bolchevista e, de forma mais ampla, a ameaça que a agitação interna, por ela provocada, representava para o país. Na competição pelas consciências, a propaganda se tornou a arma principal, argumentava. Por isso, os japoneses não podem mais continuar indiferentes ao assunto: têm de se preocupar não apenas defensivamente, mas 
desenvolvendo sua própria força naquilo que, resume ele, teria se tornado motivo de uma guerra de pensamento entre a sua visão de mundo e a do Ocidente.

Como disse seu colega Takaaki Kuwatsu, outro teórico da guerra de pensamento, tradutor da obra de Lasswell para o japonês, a propaganda de guerra, milenar, adquiriu agora contornos mundiais. A guerra moderna se tornou inseparável, em parte ao menos, da guerra de propaganda, cujos princípios, para não falar da prática, não podem mais ser desconhecidos, esclareceu e ilustrou em Guerra e guerra de pensamento pela propaganda (1939). Os movimentos de autodeterminação asiática, conquanto progressistas, precisam estudar os métodos e aprender a explorar os recursos e materiais com que se pode desenvolvê-la, até para combater a contrapropaganda daqueles que lhes fazem frente, como os revolucionários comunistas e reacionários chineses.

Chefe da divisão de operações do Comitê de mobilização espiritual nacional criado no final de 1937, Takaaki também difundiu suas ideias em vários escritos de pequena extensão, feitos para servir de manuais. Em A Guerra de propaganda moderna (1937), por exemplo, denunciou a propaganda bolchevista. Os horrores da propaganda de guerra, de 1936, revelou sua indignação com a exploração de suas técnicas com fins militares. Em A propaganda de guerra que ameaça o Japão (1937), enfim, esclareceu a importância do assunto e seus significados para o povo japonês, salientando o papel da propaganda na construção de uma nova ordem mundial, a unidade de seus aspectos diplomático e militar, e a necessidade de seu país estar alerta para a propaganda pela força tanto quanto a força da propaganda.

Yoshizumi Awaya (1900-1980), pioneiro do estudo da publicidade comercial e nome de crescente projeção no negócio após o final da II Guerra, que traduziu para o japonês o clássico de Claude Hopkins, A publicidade científica ([1923] 1939), acompanhou-lhe os passos. Autor de um volumoso tratado sobre os princípios conceituais e técnicas de sua profissão (Teoria da publicidade, 1933), reuniu ele em Guerra e Propaganda (1939) seus numerosos textos sobre a propaganda nas relações internacionais.

Sua tese era a de que a propaganda possui uma magia própria e está, em essência, voltada para a pacificação dos espíritos, mas não se deve temer usar todos os meios por ela 
conhecidos para defender uma causa que exija o emprego da força (HIGH, 2003, p. 139). Os japoneses precisam estar alertas e não podem ficar inertes diante da ameaça representada, no interior, pela propaganda comunista, influenciada pelo judaísmo internacional, e, no exterior, pela propaganda antijaponesa, promovida pelos nacionalistas chineses.

Para ele e tantos outros, a hora era a de ajudar o governo engajando o povo na guerra de pensamento. Havia chegado o tempo de a nação pensar seu modo de vida e até seu lazer não mais individualmente. Como ocorria já com a educação, também estes setores deveriam ser vistos como forma de unir as pessoas em função de um objetivo comum. Yoneyama Keizō (1906-1979), autor de Guerra de pensamento e propaganda (1943), recorreu ao conceito ocidental de ideologia para teorizar e desenvolver esta perspectiva. Segundo ele, a opinião pública tende a se desintegrar em massas, com avanço da economia moderna. As massas se tornam objeto de disputa por parte das forças políticas, todas tentando lhe impor a sua própria opinião. A guerra que assim se estabelece assume caráter mundial na medida em que é travada com a ajuda de armas, sobretudo o telégrafo e o rádio, que permitem ao pensamento vencer o tempo e o espaço, mas também converter-se em força material, como alertavam os intelectuais marxistas.

A propaganda é a arte de combinar a informação responsável e motivadora entre os amigos com uma estratégica de desinformação e política de advertência para os inimigos. O viés nipônico pode ser identificado contrapondo-se às ideologias liberal e nazista. Apesar de a visão de mundo nacional-socialista não se coadunar de todo com os preceitos do viés japonês e oriental, ela está mais próxima deste último, visto os problemas e prejuízos inerentes à forma democrática ocidental. A singularidade da abordagem japonesa residiria em, baseando-se em laços espirituais de irmandade comunitária e fidelidade à família e à tradição imperial, privilegiar a política cultural coletivamente responsável, em vez do emprego da trapaça e da imposição mecânica de cima para baixo, supostamente dominante no Ocidente.

Yoneyama era um dos membros da "Sociedade para o Estudo das Técnicas Publicísticas", criada no início de 1940, com o objetivo de promover a pesquisa em tecnologia de propaganda e, assim, ajudar a "unificar o país e o povo". Deste grupo, 
faziam parte notáveis das maiores universidades, assim como políticos e profissionais das áreas de jornalismo e publicidade, muitos racistas (cf. KUSHNER, 2006, p. 68-84; MOORE, 2013). Para seus integrantes, "a única forma de o Japão vencer a guerra contra a China era o país adotar uma ideologia mais totalitária, entendida como fusão entre os objetivos individuais e as aspirações nacionais", como dizia o publicitário Imaizumi Takeji (apud KUSHNER, 2006, p. 69; MIMURA, 2011, p. 184-186).

Acreditando que o termo propaganda invocava uma imagem negativa, associada a manipulação, fraude e controle da mente, alguns membros do grupo polemizaram quando, em 1942, a sociedade mudou seu nome para "Associação Japonesa para a Cultura da Propaganda". De acordo com o modo de ver destes integrantes, conviria evitar o uso deste termo, falar em "meios técnicos de expressão", por exemplo. O primeiro conceito carregaria conotações tão negativas que, em seu entender, "não se coadunava com as ideias que o Japão desejava promover internacionalmente, além do fato de ser desnecessário, visto os integrantes do Império serem um único povo, [desconhecerem divisões]" (KUSHNER, 2006, p. 71).

\section{Koyama Eizō - a mente mestra}

Presidida pelo historiador Soho Takutomi, a sociedade, vimos, tinha um cunho paragovernamental e se propunha, conforme as palavras daquele primeiro, a enfrentar a propaganda inimiga, reformar a visão de mundo japonesa e promover a guerra de pensamento para, assim, "incentivar a opinião pública a apoiar a continuação da guerra [de material]" (MENDELSSOHN, [1944] 2011, p. 58).

Entre os principais animadores do grupo, merece especial menção o nome de Koyama Eizō, responsável pelas publicações e, a partir de 1944, presidente da associação. O autor fez longa e produtiva carreira em várias áreas acadêmicas, começando pela de estudos do jornalismo. Após sua nomeação para ocupar cátedra na Universidade Rikkyo de Tókio (1937), ele voltou-se com mais ênfase para os estudos de psicologia social e etnologia, passando a colaborar ativamente com o Comitê de Informação. 
O autor [tinha então] uma única preocupação, cujo projeto de estudo poderia ser descrito (em seus próprios termos) como uma 'engenharia étnica' (minzoku kosaku). Em sua visão, os estados-nação dos tempos modernos eram sociedades de massas, feitas de hordas vastas, complexas e volúveis. A tarefa da ciência social seria transformar estas massas em uma forma visível e compreensível, a fim de ser reformatada, redesenhada e aprimorada. O segredo para tornar a sociedade visível residiria na coleta e análise de dados em grande escala - na mensuração das [...] opiniões e das crenças. A mídia era essencial para tanto, porque seria o canal através do qual as ideias eram produzidas e consumidas em massa (MORRIS-SUZUKI, 2000, p. 505).

Koyama começou a se ocupar com o assunto que nos ocupa em 1938, procedendo a um estudo sistemático dos fundamentos do fenômeno em seu volumoso tratado Teoria das técnicas de propaganda. Sociólogo de formação, o autor observa a necessidade de, ao tratar do tema, não perder de vista uma disciplina epistemológica. O fenômeno da propaganda adquiriu relevo com sua exploração militar e emprego pelos regimes totalitários, modificando o curso das relações internacionais. A política de informação que os governos precisam levar adiante a partir de agora, todavia, não comporta mais amadorismo e improvisação.

Já que a conduta social humana é mediada pela consciência, controlar a consciência é controlar a conduta. O meio para controlar a consciência é a propaganda - o problema consiste em saber como se estrutura esta manipulação (KOYAMA apud MORRIS-SUZUKI, 2000, p. 511).

Depois dele houve, note-se, outros que, laborando academicamente, se propuseram a sistematizar o conhecimento disponível sobre a matéria, como o cientista político Tetsuhiko Tosawa. Em Introdução à propaganda (1942), por exemplo, apresenta ele os princípios de análise do que conceitua como atividade que visa influenciar a atitude ou a conduta de um grupo. O texto apresenta os métodos da propaganda e comenta a tendência a usar as notícias como forma encoberta, sem deixar de examinar seus vários veículos, dos jornais às histórias em quadrinhos.

Koyama era bem mais ambicioso e bem menos propenso ao discurso imediatista, embora tenha escrito manuais de orientação técnica, como Guerra de pensamento e propaganda 
(1940), e estratégica, como Teoria da propaganda de guerra (1942), para não falar de sua contribuição à coletânea, ao mesmo tempo muito técnica e conceitualmente avançada para a época, intitulada As tecnologias da propaganda (1943). Para ele, a propaganda consiste, essencialmente, em um conjunto de técnicas para formatar a consciência social de acordo com uma visão de mundo. A fim de vencer na guerra, "era indispensável conferir a uma ideia clara, poderosa e internamente coerente a capacidade de liderar a opinião pública de toda a nação" (KOYAMA apud YOSHIMI, 2002, p. 206).

A propaganda é uma forma de ação com que se estrutura ou organiza a opinião pública em uma era de massas. A agitação tem sentido puramente destrutivo e não serve à criação de coletivos úteis em médio prazo. "A propaganda é luta pela 'hegemonia ideológica': ela deve reunir o povo em torno de um único e mesmo objetivo e conceito de sociedade" (KUSHNER, 2006, p. 33-34).

Apesar de examinar variáveis materiais, estéticas e logísticas, os meios e formatos intervenientes na ação propagandística, o foco do autor está em sua teorização como processo psicossociológico, não faltando espaço para uma análise de seu suposto alcance e efeitos e sobre seu eventual método de mensuração em seu rico e detalhado "Teoria das técnicas da propaganda" (1937). Os mecanismo por ela explorado é o da psicologia de massas: a sugestão; e seu substrato último, irracional: as sensações, sentimentos, emoções e impressões com as quais se associam os conceitos e objetivos por ela trabalhados. A propaganda é função da política de informação, mas seu fundamento é psicológico, e seu sucesso não depende apenas do trabalho de organização de cima para baixo, como teria sido defendido nos regimes totalitários.

Koyama argumentava de início que os estratos profundos tinham influência permanente na conduta das pessoas. Os meios possuiriam o poder de construir a consciência da realidade e, assim, influenciar a opinião majoritária em dada direção. Ainda em seu livro de 1935 sobre a imprensa, reconhecera ele a possibilidade do emprego desta última como meio de persuasão e liderança, como advogavam os teóricos alemães do período. No tratado sobre a propaganda de 1937, ele argumenta que a propaganda é um conjunto de técnica capaz de instituir a aparência de um único e mesmo coletivo, quando de fato se está diante de pessoas estranhas e distantes umas das outras (SCHÄFER, 2012, p. 164). 
Conforme o conflito com a China foi se prolongando e se aprofundava seu engajamento pessoal no esforço militar japonês, o autor começou a revisar seu primeiro entendimento. Em meio à conjuntura de avanço do imperialismo e, em seguida, guerra com o Ocidente, sua fenomenologia da propaganda passou a ter acento essencialmente pragmático. A responsabilidade do liberalismo no reforço das divisões sociais inerentes à dinâmica da modernidade e, assim, na gênese do antídoto que representa a propaganda se tornou razão para advogar em favor do seu emprego com vistas à criação de uma opinião pública firme, coerente e convicta por parte da liderança nacional.

O principal, no entanto, é que a propaganda, conjunto de técnicas para modelar a consciência e pôr as pessoas sob um mesmo conceito e dinâmica espiritual, passou a ser vista como processo que, examinado desde a ótica a ser aplicada internamente, se estrutura de baixo para cima. O propagandista que se conduz sem examinar a ótica do público é como o médico que prescreve remédio sem examinar o paciente. O papel do propagandista em relação ao seu concidadão, ao contrário da propaganda de guerra ou colonial, feita para os outros, deve se limitar à ajuda no que aquele segundo precisa para organizá-la.

A propaganda não é algo dispensável apenas de cima para baixo. Também deve provir do povo, através de organizações públicas locais como associações juvenis, associações femininas, assembleias locais etc. Esta propaganda oriunda das instituições sociais comunitárias é mais efetiva [do que aquela oriunda do governo no plano interno] (KOYAMA apud SCHÄFER, 2012, p. 164).

Do primeiro tratado sobre a propaganda, provinha o postulado de que, sob o estado sólido da opinião, havia um substrato profundo, de caráter genético e instintivo. Explorando as implicações de sua posterior especulação etnológica, emergiu sua reinterpretação pragmática a respeito. O referido substrato não é universal, representando, antes, uma herança étnica de sentido espiritual diferente para cada povo. A propaganda é um conjunto de técnicas, sim, mas se estrutura e opera em função de uma "personalidade comunitária nascida de uma comunidade de destino na qual as características das várias 
culturas espirituais e culturais encontram suas características étnicas exclusivas" (KOYAMA apud SCHÄFER, 2012, p. 165).

A propaganda se baseia sempre nos mesmos mecanismos mas, por isso mesmo, varia em forma conforme o contexto étnico em que se desenvolve. Os japoneses se encontram em guerra de pensamento e não apenas de material com os ocidentais. A pesquisa etnológica dos povos sob sua influência pode ajudar as lideranças militares a melhor entenderem seu modo de pensar e, assim, orientar com mais chances de sucesso as estratégias de propaganda nacional no âmbito do Império (cf. MORRIS-SUZUKI, 2000, p. 504-513).

\section{Conclusão}

“O Japão da época da guerra escapou do pesadelo que representa uma sociedade de massa sem raízes e escravizada por instituições altamente centralizadas" (HAVES, 1978, p. 21) - o juízo, fato ou não, endossa o entendimento que as autoridades e lideranças japonesas daquele tempo faziam a respeito de seu povo e seu país ao se mobilizarem para enfrentar a guerra de pensamento que, segundo todos eles, o mundo estava vivendo (cf. HIDEYA, 1955, p. 24).

A propaganda japonesa dirigida aos povos asiáticos revestiu-se de um cinismo marcado pela brutalidade que a guerra de conquista e exploração impunha mas, note-se, dele não estavam livres os próprios cidadãos do país, cuja consciência militarista, formada ao longo de séculos, assumira feições imperialistas no final do século XIX. As propagandas interna e para o estrangeiro possuíam uma unidade: "não havia uma linha dividindo claramente as propagandas doméstica e externa, apesar de a apresentação e os giros de um argumento serem inevitavelmente diferentes, conforme ele fosse dirigido para dentro ou fora do país" (JANG, 2007, p. 66).

A postulação de que, através dos canais e técnicas daquela primeira, eles foram simplesmente enganados pelas autoridades ou, em condições repressivas, engajados em uma mistificação artificiosa aparentemente não se sustenta. A manipulação de informação 
da qual nenhuma ação propagandística, por definição, está livre estava, por certo, sempre presente no detalhe (HIGH, 2003, p. 139-140) mas seria um erro, parece, pensar que, assim, o povo japonês, em sua maior parte, estivesse sendo corrompido em suas crenças e alienado em seus objetivos como coletivo em termos epocais (cf. KIM, 2013).

"No Japão, ao contrário dos países totalitários, associações [civis] responsáveis por um controle burocrático intermediário se associaram a um oligopólio de empresas privadas autorizado pelo estado [no tocante ao desenvolvimento da propaganda]", afirma Kasza (1988, p. 288). Para o autor, a máquina de propaganda não sofreu dos prejuízos decorrentes de um controle total por parte do estado. "A colaboração dos jornais com as autoridades responsáveis pela censura foi, em geral, fluente e raramente houve necessidade de advertir ou punir um jornal. Assim, nenhum grande jornal foi fechado durante a guerra e nenhum editor de um grande diário foi preso ou processado", complementa Shillony (1981, p. 94). A propaganda interna foi, no detalhe, obra de pessoas engajadas voluntariamente no esforço de guerra e, no geral, fruto de uma coordenação burocrática firmemente apoiada pela mobilização da sociedade civil.

Ji Jung exorbita sociologicamente, em nosso ver, ao exagerar a liberdade de consciência com que o público japonês ouvia o rádio durante os anos de guerra (JUNG, 2010, p. 47). Em sua análise da forma como os comitês de propaganda se reuniam em grupos durante certas horas, está correta a conclusão de que não havia manipulação. O problema nos parece ser a falta de raciocínio histórico dialético e, assim, da capacidade de perceber o sentido deste fenômeno, pré-determinado, ainda que não totalmente, pelo cunho profundamente autoritário e, portanto, favorável à política militarista da maior parte da sociedade japonesa naquele tempos (cf. SHILLONY, 1981, p. 100; BASKETT, 2009, p. 199).

A propaganda japonesa se caracterizou por um acento militarista e se desenvolveu mais ou menos organicamente a partir "da visão tradicional, que pressupunha o sacrifício individual em favor do interesse coletivo. A desobediência e a falta de respeito para com o sistema de relações sociais derivado da ética confuciana e baseado na ideologia do kokutai (sistema nacional) comportavam não apenas sanções penais, mas uma espécie de 'ostracismo interno' para os infratores extremamente eficaz em uma sociedade orientada 
para o grupo, como era a japonesa" (DEL BENE, 2008, p. 20; cf. ainda WOLFRAM, 2007; ITO. 2003).

Valendo-nos desta premissa, podemos, por outro lado, aproveitar a análise de Jung, em especial sua observação de que o discurso japonês sobre a propaganda "considerava a participação voluntária da população [nas reuniões] a situação ideal [para que se concretizassem legitimamente seus objetivos e função". Isto é, "o movimento de audiência em grupo não almejava simplesmente forçar os ouvintes a absorver certas mensagens em situação de intensa vigilância". O engajamento voluntário e aberto dos ouvintes era considerando "medida essencial para promover o aprendizado interativo [daquelas mensagens] entre os participantes" (JUNG, 2010, p. 35; cf. DANIELS, 1982).

Por isso, convém matizar a visão ocidental mais antiga, segundo a qual o estado pura e simplesmente controlaria uma opinião pública capaz de julgar seus atos de acordo com o ponto de vista da sociedade civil se não fosse subjugada pelas autoridades, como se vê, por exemplo, em Nobutaki (1957, p. 223-224). O esquema talvez valha para nossas realidades, mas não se aplica ao caso japonês durante o período estudado. A propaganda aparentemente não visava adornar uma política de terror, nem a imprensa foi meramente "submetida à pressão, para moldar seus conteúdos de acordo com as linhas ideológicas inspiradas pelo oficialismo" (p. 224).

Provavelmente, o objetivo de vencer o racismo e liberar os povos asiáticos da dominação ocidental jamais tenha realmente convencido o povo japonês como motivo para seu país ter agredido outros e lhes invadido os territórios. $\mathrm{O}$ fato de a propaganda ter ajudado a criar um relacionamento simbiótico entre as tropas e a população civil, vincular as frentes externa e interna em que ele estava comprometido, sem recurso à grande coerção dentro da última, entretanto, não pode ser negado. As autoridades governamentais não se impuseram arbitrariamente, nem o apoio popular que obtiveram foi obra de uma propaganda insidiosamente inoculada na população (KUSHNER, 2006).

Os intelectuais japoneses que se preocuparam em pensar a propaganda se valeram dos conceitos, noções e técnicas de origem ocidental mas, como tendeu a ocorrer na prática, a interpretaram de acordo com as peculiaridades e tradições de seu país, concluindo que, 
internamente, a propaganda criada com o apoio ativo e criativo das organizações civis, emanada da base da sociedade, era a sua essência. O país deveria empregar a tecnologia de propaganda ocidental para promover a sua a seu próprio modo, porque, ao contrário do que eles supunham ser a visão de seus inimigos, a propaganda não teria como mobilizar as pessoas com fórmulas e mensagens descoladas do modo de vida das massas.

As pessoas, argumentaram, precisam se sentir participantes do / e de fato colaborarem com o processo, para ele ter eficácia e não ser desacreditado, não importa o quanto, por um observador externo, sejam quiméricas sua causa e objetivos, senão o próprio raciocínio destes intelectuais. As estruturas sociais que caucionavam não apenas seu entendimento da atividade propagandística, mas a própria inserção e sentido da mesma na vida dos súditos imperiais eram autoritárias para nós. A maioria da população e boa parte dos intelectuais as viam organicamente.

As propagandas de guerra contra os inimigos do império e de cooptação dos povos que ele veio a dominar durante os anos de conflito não podem ser separadas da propaganda feita internamente pela aliança entre a sociedade civil japonesa e os círculos militaresgovernamentais. Aí, a premissa em que se baseou o pensamento de seus teóricos era, porém, a de que sua razão de ser não seria manipular a informação, mas "informar o povo sobre a própria vontade nacional” (KUSHNER, 2006, p. 71).

Por isso, as massas japonesas provavelmente foram, até o final, muito mais sujeito do que objeto da propaganda feita em seu país, embora não se deseje aqui estabelecer uma oposição mecânica entre estas duas categorias.

\section{Referências}

AKAMI, T. Japan's news propaganda and Reuters' news empire in northeast Asia, 1870-1934. Dordrecht: Republic of Letters, 2012.

ALLEN, M.; SAKAMOTO, R. Japan popular culture. Londres: Routledge, 2014.

ASAHI SHIMBUN. Media, propaganda and politics in $20^{\text {th }}$ century Japan. Londres: Blomsbury, 2015.

BASKETT, Michael. All Beautiful Fascists? In: TANSMAN, Alan (org.). The Culture of Japanese Fascism. Durham: Duke University Press, 2009. 
BRONSON, Adam. "Science of Thought" and the Culture of Democracy in Postwar Japan, 1946-1962. (Tese de Doutorado). Nova York: Columbia University, 2012.

COOPER, Roger. Japanese communication research. Journal of Broadcasting and electronic media, v. 41, n.2, p. 284-289, 1997.

CREEL, George. How we advertise America. Nova York: Harper, 1920.

CROSS, Tim. Japanese Harmony as Nationalism. In: CROSS, Tim (org.). The ideologies of Japanese tea. Brill, 2009.

DEL BENE, Marco. Mass media e consenso nel Giappone prebellico. Milão: Mimesis, 2008.

EARHART, David. Certain victory - Images of World War II in the Japanese Media. Nova York: Sharpe, 2008.

IRIYE, Akyra. Power and culture: The Japanese-American War, 1941-1945. Cambridge: Harvard University Press, 1982.

DE LANGE, William. A history of japanese journalism. Londres: Routledge, 1997.

HAVES, Thomas. Valley of Darkness. Nova York: Norton, 1978.

HIDEYA, Komata. Spiritual mobilization. In: INSTITUTE OF COMMUNICATION RESEARCH. Four working papers in theory of propaganda. Champagne: USIS/University of Illinois, 1955.

HIGH, Peter. The imperial screen. Madison: University of Wisconsin Press, 2003.

JANG, Hoi. Japanese Imperial ideology shifting war aims and domestic propaganda during the Pacific war of 1941-1945. Nova York: State University of Nova York, 2007.

JUNG, Ji. Radio broadcasting and the politics of mass culture in transwar Japan. (Tese de Doutorado). San Diego: University of California, 2010.

KOICHI, Kanda. Shisosen to senden. Tóquio: Tachibana Shoten, 1937.

KANESADA, Hanazono. The development of Japanese journalism. Osaka: Osaka Mainichi, 1924.

KASZA, Gregory. The State and the Mass Media in Japan, 1918-1945. Berkeley: University of California Press, 1988.

KIM, Kyu. Total war mobilization and transformation of the national public sphere in Japan, 1931-1945. In KIM, M.: SCHOENHALS, M.; YONG WOO, K. (orgs.). Mass dictatorship and modernity. Londres: Palgrave, 2013.

KUSHNER, Barak. The Thought War. Honolulu: University of Hawaii Press, 2006.

MACDERMID, Susan. Print capitalism and the Russo-Japanese war. (Tese de Doutorado). Vancouver: British Columbia University, 1982.

MARTIN, F. The journalism of Japan. Jeffeson: University of Missouri Bulletin 19/10, 1918.

MENDELSSOHN, Peter de. Japan's political warfare. Abingdon: Routledge [1944] 2011. 
MIMURA, Janis. Planning for Empire. Ithaca: Cornell University Press, 2011.

MOORE, Aaron. Constructing Eats Asia. Berkeley: University of California Press, 2013.

MORRIS-SUZUKI, Tessa. Ethnic Engineering: Scientific Racism and Public Opinion Surveys in Midcentury Japan. Positions, v. 8, n. 2, p. 499-529, 2000.

NOBUTAKI, Ike. Japanese politics. Nova York: Knopf, 1957.

RÜDIGER, Francisco. Os primórdios do estudo da imprensa e da teoria do jornalismo no Japão. Estudos em Comunicação, n.22, p.1-21, 2016.

RÜDIGER, Francisco. O mito da agulha hipodérmica e a era da propaganda. Porto Alegre: Sulina, 2015.

SATO, Takumi, The System of Total War and the Discursive Space of the Thought War. In Yamanouchi, Y., Koschmann, J. Ryûichi, N. (orgs.). Total war and 'modernization'. Ithaca: Cornell University, 1998.

SCHÄFER, Fabian. Public opinion, propaganda, ideology. Leiden: Brill, 2012.

SHILLONY, Ben-Ami. Politics and culture in Japan. Nova York: Oxford University Press, 1981. SHIRATO, Kenichiro. The Origin of "A Well-Informed Hundred Million". Lifelong education and libraries, v. 10, p. 49-53, 2010.

TAKAAKI, Komatsu. Sensō to shisosendensen. Tóquio: Shunjusha, 1939. Kindaisen to puroproganda. Tóquio: Shunjusha, 1937. . Nihon o obiyakasu sendensen. Tóquio: Morita Shobō, 1937. Sensō to senden no senritsu. Tóquio: Morita Shobō, 1936.

TAKASHI, Kenmochi. The public relations of propaganda. Tóquio: Instituto japonês de estudos econômicos e sociais, 2013.

TANSMAN, Alan. The Culture of Japanese Fascism. Durham: Duke University Press, 2009.

TETSUHIKO, Tozawa. Senden gairon. Tóquio: Chuo Kōronsha, 1942.

TIPTON, Elise. Modern Japan. 2a. ed. Londres: Routledge, 2008.

TSUTSUIT, William. Soft power and the globalization of Japanese popular culture. HOLROYD, Carin; COATES, Ken (orgs.). Japan in the Age of Globalization. Londres: Routledge, 2011.

WADA-MARCIANO. Mitsuyo. Nippon Modern. Honolulu: University of Hawaii Press, 2008.

WEISENFELD, Gennifer. Publicité et propagande: le modernisme comme méthode. In TSCHUDIN, J.; HAMON, C. (orgs.). La societé japonaise devant la montée du militarisme. Paris: Picquier, 2007.

WILDES, Harry. Social currents in Japan. Chicago: Chicago University Press, 1927. 
WOLFRAM Manzenreifer. Sport et politique du corps dans le Japan totalitaire. In: TSCHUDIN, J.; HAMON, C. (orgs.). La societé japonaise devant la montée du militarisme. Paris: Picquier, 2007.

YANG, Daqing. Technology of empire. Harvard: Harvard University Asia Center, 2010.

YONEYAMA, Keizō. Shisō tōsō to senden. Tóquio: Meguro Shoten, 1943.

YOSHIMI, Shunya. The development of newspapers studies as an academic discipline in the discursive space of 1930. Japan social science journal, v. 5, n. 2, p. 199-214, 2002.

YOSHUZUMI, Awaya. Kokoku tsuron. Tóquio: Gakubundo, 1933.

Senso to senden. Tóquio: Jidaisha, 1939.

YUKA, Fusioka. The thought war. In MASATO, K.; TOSH, M. (orgs). Tumultuous decade.

Toronto: Toronto University Press, 2013.

\section{O autor}

Francisco Rüdiger é professor da Universidade Federal do Rio Grande do Sul e da Pontifícia Universidade Católica do Rio Grande do Sul. Doutor em Ciências Sociais (USP). frudiger33@gmail.com 